\title{
The impact of fatwas on patients' acceptance of enamel matrix derivatives for periodontal regeneration in Saudi Arabia
}

This article was published in the following Dove Press journal:

Patient Preference and Adherence

\section{Najla N Al-Dabbagh \\ Talal M Zahid}

Department of Periodontology, Faculty of Dentistry, King Abdulaziz University, Jeddah, Saudi Arabia
Correspondence: Talal M Zahid

Department of Periodontology, Faculty of Dentistry, King Abdulaziz University, Al-Ehtifalat Street Jeddah 22252,

Saudi Arabia

Tel +966 I2 6403316

Email tzahid@kau.edu.sa
Background: Since the introduction of enamel matrix derivatives (EMD) (Emdogain ${ }^{\circledR}$ ), it has not been allowed to be used in Saudi Arabia due to the religious restriction on porcine products. This study was conducted to determine the impact of the fatwas permitting the use of EMD and to assess the general perception of using bone-grafting materials in Jeddah, Saudi Arabia.

Materials and methods: This cross-sectional survey study included 213 patients seeking dental treatment at the Faculty of Dentistry Clinics of King Abdulaziz University, Jeddah, Saudi Arabia. They were recruited between September and November 2017. Subjects completed a questionnaire to assess their opinions before and after reading the fatwa about using EMD.

Results: Majority of the study subjects (70\%) did not accept the use of bone-grafting materials and EMD in periodontal regeneration before reading the fatwas. The highest rate of acceptance was observed for the use of tissues from one's own body (84\%) while the biomaterials of porcine origin had the lowest acceptance rate (14.1\%). Strong religious belief and low education level were the two key factors responsible for the initial refusal of EMD use before reading the fatwas. Around $45.1 \%$ of the participants changed their opinions in favor of EMD use after reading the fatwas and their interpretations. McNemar's test found a statistically significant difference in opinions collected before and after reading the fatwas $(P<0.001)$.

Conclusion: A significant impact of the fatwas was found on patients' acceptance of EMD use for periodontal regeneration. We believe reliable interpretations of the fatwas may positively shift patients' attitudes toward using new biomaterials.

Keywords: enamel matrix derivative, bone grafts, periodontal regeneration, fatwa, religion, Emdogain, EMD

\section{Introduction}

The Kingdom of Saudi Arabia is the heart of the Islamic world, as two of the most sacred cities for Muslims, Makkah and Medina, are located here. Religion plays a significant role in Saudi Arabia in setting the moral and ethical standards for general people. The perception of indigenous people toward necessary treatments are, thus, greatly influenced by the Islamic laws and ethics. ${ }^{1-3}$ Apart from the religious perspective, it has been identified that the acceptance of medical and dental treatment also depends on the educational background of patients. ${ }^{4}$ Therefore, general and dental practitioners in Saudi Arabia face many different challenges on a regular basis while treating their patients. ${ }^{5-7}$ In fact, these challenges arise more frequently during dental procedures, especially when a surgical periodontal therapy is suggested to a patient.

The periodontal therapy involves both nonsurgical and surgical techniques to restore tooth-supporting structures affected by periodontitis. The primary theme of today's 
periodontal therapy is periodontal regeneration, which is achieved using combinations of several invasive procedures. Of the various regenerative periodontal procedures, bone grafting is the most widely used technique for replacing lost or damaged soft and hard tissues. Bone grafts that are commonly used in dentistry include autografts, allografts, xenografts, and alloplasts. ${ }^{8}$ Another well-established method for the periodontal regeneration is the use of enamel matrix derivatives (EMD), also known as Emdogain ${ }^{\circledR} .9$

Autogenous bone grafts involve grafts being taken from one site and transplanted into another site of the same individual. Autografts are considered the gold standard material in today's periodontal regeneration due to their high histocompatibility, osteogenic, osteoconductive, and osteoinductive properties. The main disadvantages of utilizing these materials include limited availability, difficult harvesting technique, and postoperative donor site complications. ${ }^{10}$ Allografts are obtained from human cadavers and transplanted to a patient. These grafts are available in large quantities and can be found in various sizes and shapes. However, unlike autografts, allografts are not osteogenic and exhibit osteoconductive properties only when the decalcified freeze-dried form is used. Alloplasts are synthetic bone substitutes (eg, hydroxyapatite, bioactive glass, and tricalcium sulfate) and can be used either alone or in combination with other growth factors such as bone morphogenic proteins. Bone substitutes are, however, strictly osteoconductive and their uses are only limited to reconstruction of large bone defects. Moreover, the use of these materials in combination with biological factors may subject a patient to adverse clinical outcomes. ${ }^{10,11}$

On the other hand, xenografts and EMD have been used with varying degrees of success in the treatment of intrabony defects. Both are suggested to be potential alternatives to autografts and allografts for periodontal regeneration, considering their biocompatible properties. ${ }^{12,13}$ However, from Islamic perspective, there are several ethical issues with the use of these biomaterials, as they are retrieved from animal sources. In fact, EMD are acquired from the tooth bud of embryonic porcine, and majority of the xenografts are of bovine or porcine source. The noble Quran states that "strictly prohibited foods for consumption of dead meat, blood, the flesh of swine ... as they are unclean". ${ }^{14}$ Hence, most Muslim patients object the use of biomaterials obtained from animals, especially those from porcine origin doubting whether it is permitted within the boundaries of Islamic laws.

The noble Quran does not strictly prohibit the use of biomaterial of porcine sources for other purposes, and thus it has been highly debated among Islamic scholars whether they could be used for medical purpose. Moreover, an in-depth analysis of the fatwas regarding the use of bone grafts of animal origin suggests that they are permissible in certain circumstances. ${ }^{15}$ Fatwas are nonbinding, legal opinion by an expert jurist or mufti (scholar in Islamic law) on a specific issue where Islamic jurisprudence and rulings are not clear or explicit from the noble Quran, the Sunnah (sayings of Prophet Muhammad), or the consensus of early scholars. ${ }^{16}$ They are not religious laws and may be subjected to interpretative differences between muftis. Nevertheless, it is beyond the scope of this study to evaluate whether fatwas by most muftis unanimously agree on the use of biomaterials of porcine origin and discuss which fatwas agree or disagree regarding their use in medical context. The main purpose of this current cross-sectional study was to assess the impact of fatwas permitting the use of porcine biomaterials, specifically the acceptance of EMD, among dental patients in Jeddah, Saudi Arabia. We investigated whether the fatwas positively shifted the perception of patients requiring general and periodontal treatment.

\section{Materials and methods Study design}

The present study was designed as a multi-item, crosssectional survey. The study protocol was reviewed and approved by the Research Ethics Committee at the Faculty of Dentistry, King Abdulaziz University, Jeddah, Saudi Arabia. The questionnaire was developed following the suggestions by Boynton and Greenhalgh, ${ }^{17}$ and a small working group committee validated it. A pilot study was conducted on 10 students of the King Abdulaziz University to ensure clarity and unambiguousness of the questions. Any question that seemed confusing or unclear to the participants was either rephrased or omitted.

\section{Patient selection}

Our target population were patients seeking general dental treatment, nonsurgical periodontal therapy, or periodontal regeneration surgeries. Two hundred and thirteen patients (178 general patients and 35 periodontal patients) were recruited within a 3-month period (between September and November 2017). The inclusion criteria included patients aged between 18 and 60 years and with full dentition or partial edentulism (minimum 15 teeth). The exclusion criteria included non-Muslim, mentally unstable, or completely edentulous patients.

Patients were approached in the waiting area of the undergraduate and postgraduate clinics at the Faculty of 
Dentistry (King Abdulaziz University). The study aims and objectives were clearly explained to the participated patients, and written informed consent was obtained from each subject in a private setting. Patients were also informed that they could opt out at any stage and there would be no impact on their treatment.

\section{The questionnaire}

The questionnaire included 32 questions including statements to be commented upon. The participants of the study were initially asked a set of questions regarding their sociodemographics, general health, oral hygiene routines, smoking habits, education level, and religious perspective. The respondents were asked to self-classify themselves based on their adherence to basic Islamic practices. Subjects were asked to share their opinions on the use of bone-grafting materials from different animal sources.

Fatwas of different scholars on the use of EMD were then showed to them. To determine the impact of fatwas, participants' opinions were collected before and after reading the fatwas. The questionnaire-based interviews were carried out by two investigators. The questionnaires were filled on the spot, and all responses from participants were entirely voluntary.

\section{Data analysis}

Continuous data such as age were expressed as mean $\pm \mathrm{SD}$ while categorical variables were expressed as frequency counts and percentages. Categorical data were compared using chi-squared test or Fisher's exact test where appropriate. McNemar's test was used to compare the percentage of patients accepting biomaterial use before and after reading the fatwas. This test was carried out to assess whether the fatwas significantly affected their opinions.

Two generalized linear models were constructed using the bias reduced logistic regression. One model was built to assess factors associated with the refusal to use products from porcine and other sources before reading the fatwas. Another model was created to determine factors that predict the change in opinion after reading the fatwas. In the first model, all patients were included; however, the second model was made up of those who did not accept the use of EMD before reading the fatwas.

For analysis purpose, patients with bachelor's degree and higher were considered having high education level and those with below bachelor's degree as having low education level. In addition, for the ease of $P$-value calculation, the committed and conservative religious groups were merged into one group and the conservative to open and open groups formed another group. $P$-values less than 0.05 were considered statistically significant. Statistical analysis was performed using R Studio (version 3.2, RStudio Inc., Boston, MA, USA). Plots were also constructed by the same software.

\section{Results}

A total of 213 patients (69 men and 144 women) completed the survey questionnaire. Table 1 illustrates demographic data of the participants recruited into the study. The mean age of the participants was $34.41 \pm 12.23 \mathrm{SD}$. The majority of the subjects were Saudi nationals (78.8\%), and the remaining (21.2\%) were from various Middle Eastern and North African countries such as Egypt, Sudan, Ethiopia, and Palestine. Around $81 \%$ of the participants were nonsmokers while the percentages of current smokers and ex-smokers were $13.7 \%$ and $5.7 \%$, respectively.

Nearly $42 \%$ of the participants reported no dental disease/ condition while around $9.9 \%$ were unaware of any problems.

Table I Demographics of the study population $(n=2 \mid 3)$

\begin{tabular}{|c|c|c|c|}
\hline Variable & Value & $\mathbf{n}$ & $\%$ \\
\hline \multirow[t]{3}{*}{ Gender } & Female & 144 & 67.61 \\
\hline & Male & 69 & 32.39 \\
\hline & Total & 213 & 100 \\
\hline \multirow[t]{8}{*}{ Highest education } & $\mathrm{PhD}$ & 4 & 1.88 \\
\hline & Master's degree & 8 & 3.76 \\
\hline & Bachelor's degree & 112 & 52.58 \\
\hline & High school & 62 & 29.11 \\
\hline & Intermediate & 16 & 7.51 \\
\hline & Primary & 8 & 3.76 \\
\hline & None & 3 & $\mathrm{I} .41$ \\
\hline & Total & 213 & 100 \\
\hline \multirow[t]{5}{*}{ Economic status } & High class & 44 & 20.66 \\
\hline & Middle class & 101 & 47.41 \\
\hline & Low class & 67 & 31.46 \\
\hline & Missing & I & 0.47 \\
\hline & Total & 213 & 100 \\
\hline \multirow[t]{6}{*}{ Job status } & Full time & 65 & 30.52 \\
\hline & Part time & 17 & 7.98 \\
\hline & Retired & 17 & 7.98 \\
\hline & I do not work & 112 & 52.58 \\
\hline & Missing & 2 & 0.94 \\
\hline & Total & 213 & 100 \\
\hline \multirow[t]{5}{*}{ Marital status } & Married & 128 & 60.09 \\
\hline & Divorced & 5 & 2.35 \\
\hline & Widowed & I & 0.47 \\
\hline & Single & 79 & 37.09 \\
\hline & Total & 213 & 100 \\
\hline
\end{tabular}


Table 2 Participants' knowledge on the use of bone materials in periodontal regeneration

\begin{tabular}{l|l|l|l|l|l|l}
\hline \multirow{2}{*}{ Variable } & \multirow{2}{*}{ Value } & \multicolumn{3}{|l|}{ Heard of biomaterials } & \multirow{2}{*}{ P-value } \\
\cline { 3 - 6 } & & No & \multicolumn{3}{l}{ Yes } & \\
\cline { 3 - 6 } & & $\mathbf{n}$ & $\%$ & $\mathbf{n}$ & $\%$ & \\
\hline \multirow{4}{*}{$\begin{array}{l}\text { Religious } \\
\text { side }\end{array}$} & Committed & 27 & 100 & 0 & 0 & \multirow{2}{*}{$0.008^{*}$} \\
\cline { 2 - 6 } & Conservative & 78 & 95.12 & 4 & 4.88 & \\
\cline { 2 - 6 } & $\begin{array}{l}\text { Conservative } \\
\text { to open }\end{array}$ & 80 & 91.95 & 7 & 8.05 & \\
\cline { 2 - 6 } & Open & 12 & 70.59 & 5 & 29.41 & \\
\cline { 2 - 6 } & Total & 197 & $92.4 \%$ & 16 & $7.6 \%$ & \\
\hline \multirow{4}{*}{$\begin{array}{l}\text { Higher } \\
\text { education }\end{array}$} & Yes & 110 & 88.71 & 14 & 11.29 & \multirow{2}{*}{$0.016 *$} \\
\cline { 2 - 6 } & No & 87 & 97.75 & 2 & 2.25 & \\
\cline { 2 - 6 } & Total & 197 & $92.4 \%$ & 16 & $7.6 \%$ & \\
\hline
\end{tabular}

Note: *Statistically significant difference $(P<0.05)$.

Among patients with dental problems, gum bleeding (29.11\%) was the most predominant problem, followed by gum pain (17.84\%) and gum recession (3.3\%). Other health problems that were common among the subjects included hypertension (14.1\%), dyslipidemia (13.62\%), diabetes $(10.33 \%)$, and bone disease $(8 \%)$.

A significant percentage of the participants $(92.5 \%)$ stated that they never heard of periodontal regenerative procedures that involve the use of bone materials and/or EMD (Table 2). However, the statistics varied significantly between participants with varied religious perspectives $(P=0.008)$. While none of the subjects who described their religious perspective as committed heard of bone materials use in periodontal therapy, $29.41 \%$ participants with an open perspective were aware of such treatment procedures. Furthermore, participants with a higher education level were more likely to have prior knowledge of bone materials use than those with a lower education level (11.3\% vs $2.25 \%$, respectively, $P=0.016$ ).

Before reading the fatwas, opinions of nearly $70 \%$ participants were predominantly negative toward the acceptance of bone materials and EMD from various sources (Table 3). However, there was a statistically significant association between participants' religious perspectives and readiness to accept biomaterials $(P<0.001)$.

The use of tissues from one's self had the highest rate of acceptance among participants (84\%). In contrast, the lowest rate of acceptance was observed for the use of biomaterials from porcine origin (14.1\%). This trend of poor acceptance of porcine materials was dominant across various religious groups, including committed (3.7\%), conservative (3.7\%), and conservative to open (17.24\%). However, an exception was seen in those with an open perspective. Of this group, $64.71 \%$ said "yes" to biomaterials of porcine origin.

After reading the fatwas, a considerable change in opinion was observed among respondents from all religious groups. Overall, nearly $76 \%$ participants expressed their acceptance toward using biomaterials for periodontal regeneration. The highest change in opinion was seen in those with a committed perspective: around $81.5 \%$ changed their opinions in favor of EMD use after reading the fatwas. Figure 1 shows the change in opinion among subjects before and after reading fatwas.

Table 3 Opinions of participants regarding biomaterial use from various sources (before reading the fatwas)

\begin{tabular}{|c|c|c|c|c|c|c|c|c|c|c|}
\hline \multirow[t]{2}{*}{ Variable } & \multirow[t]{2}{*}{$\begin{array}{l}\text { Accept } \\
\text { use }\end{array}$} & \multicolumn{2}{|c|}{$\begin{array}{l}\text { Committed } \\
(n=27)\end{array}$} & \multicolumn{2}{|c|}{$\begin{array}{l}\text { Conservative } \\
(n=82)\end{array}$} & \multicolumn{2}{|c|}{$\begin{array}{l}\text { Conservative } \\
\text { to open }(n=87)\end{array}$} & \multicolumn{2}{|c|}{$\begin{array}{l}\text { Open } \\
(n=17)\end{array}$} & \multirow[t]{2}{*}{$P$-value } \\
\hline & & n & $\%$ & $\mathbf{n}$ & $\%$ & $n$ & $\%$ & n & $\%$ & \\
\hline \multirow[t]{2}{*}{ General opinion } & Yes & 0 & 0 & 18 & 21.95 & 33 & 37.93 & 14 & 82.35 & $<0.00 I^{*}$ \\
\hline & No & 27 & 100.00 & 64 & 78.05 & 54 & 62.07 & 3 & 17.65 & \\
\hline \multirow[t]{2}{*}{ Source: horse } & Yes & 9 & 33.33 & 33 & 40.24 & 49 & 56.32 & 13 & 76.47 & $0.007^{*}$ \\
\hline & No & 18 & 66.67 & 49 & 59.76 & 38 & 43.68 & 4 & 23.53 & \\
\hline \multirow[t]{2}{*}{ Source: cow } & Yes & 9 & 33.33 & 30 & 36.59 & 45 & 51.72 & 11 & 64.71 & 0.0442 \\
\hline & No & 18 & 66.67 & 52 & 63.41 & 42 & 48.28 & 6 & 35.29 & \\
\hline \multirow[t]{2}{*}{ Source: pig } & Yes & I & 3.70 & 3 & 3.66 & 15 & 17.24 & 11 & 64.71 & $<0.00 I^{*}$ \\
\hline & No & 26 & 96.30 & 78 & 95.12 & 72 & 82.76 & 6 & 35.29 & \\
\hline Missing & & 0 & 0 & 1 & 1.22 & 0 & 0 & 0 & 0 & \\
\hline \multirow[t]{2}{*}{ Source: self } & Yes & 21 & 77.78 & 69 & 84.15 & 73 & 83.91 & 16 & 94.12 & 0.5563 \\
\hline & No & 6 & 22.22 & 13 & 15.85 & 14 & 16.09 & I & 5.88 & \\
\hline \multirow{2}{*}{$\begin{array}{l}\text { Source: } \\
\text { someone else }\end{array}$} & Yes & 17 & 62.96 & 39 & 47.56 & 62 & 71.26 & 13 & 76.47 & $0.0079 *$ \\
\hline & No & 10 & 37.04 & 43 & 52.44 & 25 & 28.74 & 4 & 23.53 & \\
\hline
\end{tabular}

Note: $*$ Statistically significant difference $(P<0.05)$. 


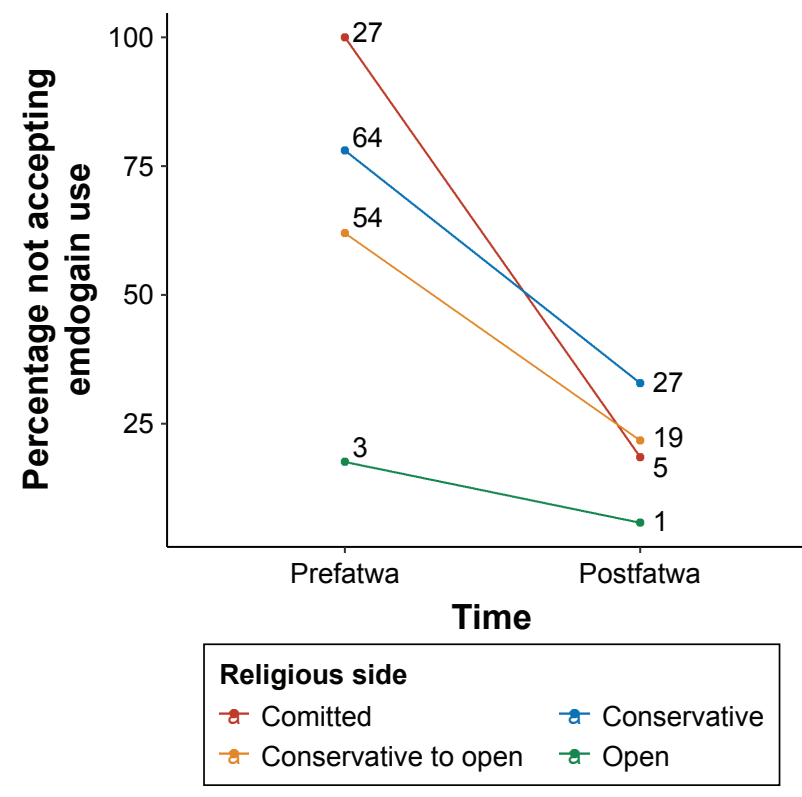

Figure I Graph illustrating participants opinions regarding enamel matrix derivatives use before and after reading the fatwas.

Notes: $Y$ axis shows the percentage of participants refusing biomaterial use The lines illustrate the number of participants refusing biomaterial use.

In addition, McNemar's test demonstrated a statistically significant difference in participants' opinions before and after learning the fatwas $(P<0.001)$. Around $45.1 \%$ subjects changed their opinions toward accepting EMD after reading the fatwas while only $24.4 \%$ did not change their opinions. In general, the most common reason for the refusal was religion as expressed by $81.21 \%$ of the subjects. This was followed by personal reasons (15.43\%) and health reasons (3.4\%), respectively.

Table 4 illustrates independent predictors responsible for participants' refusal of bone material use. Logistic regression indicates that participants with a committed or a conservative religious perspective were 2.1 times more likely to reject bone material use for periodontal regeneration than those with a conservative-to-open or an open perspective. In addition, subjects with lower education level were more likely to refuse bone material use than those with higher education level.

\section{Discussion}

The present study was designed to assess the impact of fatwas permitting the use of EMD among patients seeking dental treatment at the Faculty of Dentistry, King Abdulaziz University, Saudi Arabia.

In this study, majority of the participants (92.5\%) across all religious groups stated that they never heard of bone materials and/or EMD. Compared to a survey ${ }^{18}$ conducted in Saudi Arabia in 2010 where $66.4 \%$ subjects reported that they knew about dental implant, our result indicates that the level of awareness among Saudi dental patients regarding bone grafting and/or EMD is significantly low. This may be due to the fact these treatment options are relatively new in the dental clinics of Saudi Arabia. Another reason for the unawareness among patients could be the lack of coverage in Saudi print and electronic media about periodontal regenerative procedures.

Participants' opinions collected before reading the fatwas showed a statistically significant association between religious perspectives of the subjects and the acceptance/ refusal of biomaterials. In fact, patients with a committed or a conservative perspective were two times more likely to refuse biomaterials/EMD use than those with a conservativeto-open or an open perspective. This implies that compared to those with an open perspective, patients with a strong religious perspective have a higher likelihood to avoid treatment when there is a doubt regarding its permissibility within the boundaries of Islamic beliefs. This finding also suggests that a majority of those who refused the use of EMD did so mainly due to the fear of violating religious laws.

Religious and ethical concerns associated with the use of bone materials have not only been raised in Muslim majority countries..$^{19,20}$ In a recent study conducted on 100 Chilean patients who were mostly Christians, it was found that allograft and xenograft bone materials elicited the highest refusal rate among participants ( $20 \%$ and $15 \%$, respectively), whereas autologous grafts and alloplastics (3\% and 2\%, respectively) resulted the lowest rate of refusal. ${ }^{21}$ Religious

Table 4 Summary of logistic regression analysis to identify independent predictors for not accepting bone material use ( $n=2 \mid 3$ )

\begin{tabular}{|c|c|c|c|c|c|c|c|}
\hline \multirow[t]{2}{*}{ Variable } & \multirow[t]{2}{*}{ Estimate } & \multirow[t]{2}{*}{ SE } & \multirow[t]{2}{*}{ Statistic } & \multirow[t]{2}{*}{$P$-value } & \multirow[t]{2}{*}{ OR } & \multicolumn{2}{|c|}{ Confidence interval } \\
\hline & & & & & & $2.5 \%$ & $97.5 \%$ \\
\hline Intercept & 2.021 & 0.499 & 4.050 & 0.000 & 7.548 & 3.090 & 26.195 \\
\hline Higher education & -0.664 & 0.333 & -1.992 & 0.046 & 0.515 & 0.255 & 0.975 \\
\hline Committed or conservative & 0.742 & 0.333 & 2.230 & $0.026^{*}$ & 2.100 & 1.112 & 4.246 \\
\hline Periodontal patient & 0.150 & 0.429 & 0.349 & 0.727 & 1.161 & 0.516 & 2.882 \\
\hline Saudi nationality & -1.309 & 0.498 & -2.629 & $0.009 *$ & 0.270 & 0.080 & 0.664 \\
\hline
\end{tabular}

Note: *Statistically significant, $P<0.05$. 
belief was one of the reasons for the refusal of various types of bone graft, although the percentage of such respondents was considerably low. However, this study was conducted in a population predominated by Catholics and Evangelicals, and these Christian subgroups allow the use of grafts derived from humans and animals, which might explain this low percentage of refusal. In contrast, a study conducted in Turkey, which has a majority of Muslims, stated that Porcine-derived xenografts were rejected specifically for religious reasons by $84.6 \%$ of the participants. $^{22}$

Independent factors that significantly influenced the patient's initial refusal of bone grafts of animal origin before reading the fatwas were strong religious belief and low educational background. While around $84 \%$ of the participants expressed to use their own tissues for periodontal regeneration, the use of bone grafts from porcine origin had the lowest acceptance rate among subjects. This result confirms what Darwish $^{23}$ stated that most Muslim patients are usually not comfortable with the use of any medical or dental products of animal origin. Another striking observation from our study is that participants with a high education level were less likely to refuse bone-grafting materials/EMD use than those with a lower education level. This finding further emphasizes the value and influence of the education level in any country.

This survey found a considerable great impact of the fatwas. It was revealed that around $45.1 \%$ of the subjects changed their opinions in favor of EMD use after learning the fatwas that permit their use. This result suggests that most participants who initially gave negative opinions before reading the fatwas did so without even knowing the actual interpretation of the fatwas. They were merely uncertain that EMD might be permitted from Islamic perspective. This reflects the fact that most Muslim patients are highly sensitive regarding their religious views and prefer to avoid any medical or dental material that does not conform to the Islamic laws. ${ }^{19,23,24}$ Therefore, more emphasis on patients' education and awareness regarding the fatwas and their actual definite interpretations should be carried out.

Around $24.4 \%$ of the participants who initially refused the use of EMD did not alter their opinions even after reading the fatwas and their interpretations. This finding shows that nearly one-fourth of the subjects were not persuaded to use those materials despite their enlightenment with the fatwas permitting their uses. Although it was unknown why these participants opted to remain with their earlier opinions, the most plausible explanation for their refusals might be the deep-rooted fear of violating their religious values. Further unrecognized explanations such as personal and/or health reasons need to be explored and inspected.
Possible limitation of this study would be case selection since this study was conducted on a selected pool of patients who were seeking dental treatment at the outpatient clinics of the Faculty of Dentistry, King Abdulaziz University, Jeddah, Saudi Arabia. Given the difficulty to recruit study subjects, sample size was considered relatively small. For this reason, the outcome of this study cannot be representative of the whole Saudi population. Another limitation of our research was the mode of administration of the questionnaire. Majority of the subjects were unfamiliar with any bone-grafting materials and needed to be educated in order to complete the survey. As a consequence, their responses may be subjected to a certain degree to interviewer bias.

\section{Conclusion}

In conclusion, our data demonstrate that fatwas had a significant impact on Saudi patients' inclination to accept EMD for periodontal regeneration. We believe that authentic interpretations of the fatwas may positively shift patients' attitude toward using these bone-grafting materials. Nevertheless, it is essential to educate patients regarding the safety and benefits of using these bone-grafting materials along with the fatwas that permit their use. It is highly recommended to focus on implementing effective educational methods to increase the community's awareness regarding the significance of various bone-grafting materials in periodontal therapy and the correct interpretation of the fatwas permitting their use. In addition, medical researchers need to involve Muslim jurists to move beyond the realm of fatwas and start moving into the realm of specifics and policymaking. Finally, future studies should be directed toward a multicenter cross-sectional study executed in different regions of the kingdom aiming to reach a larger sample size and a more meticulous case selection to achieve legitimate results and increase the validity of the study.

\section{Acknowledgments}

The authors would like to thank Dr. Rufaida Quqandi and Dr. Weaam Dabroom who helped with data collection and entry.

\section{Disclosure}

The authors report no conflicts of interest in this work.

\section{References}

1. Alkabba AF, Hussein GM, Albar AA, Bahnassy AA, Qadi M. The major medical ethical challenges facing the public and healthcare providers in Saudi Arabia. J Family Commun Med. 2012;19(1):1.

2. Saeed KS. How physician executives and clinicians perceive ethical issues in Saudi Arabian hospitals. J Med Ethics. 1999;25(1):51-56. 
3. El Bcheraoui C, Basulaiman M, Wilson S, et al. Breast cancer screening in Saudi Arabia: free but almost no takers. PLoS One. 2015;10(3): e0119051.

4. Al-Turki YA, Al-Fraih YS, Jalaly JB, et al. Knowledge and attitudes towards cardiopulmonary resuscitation among university students in Riyadh, Saudi Arabia. Saudi Med J. 2008;29(9):1306-1309.

5. El Bcheraoui C, Tuffaha M, Daoud F, et al. Access and barriers to healthcare in the Kingdom of Saudi Arabia, 2013: findings from a national multistage survey. BMJ Open. 2015;5(6):e007801.

6. El Bcheraoui C, Tuffaha M, Daoud F, et al. Low uptake of periodic health examinations in the Kingdom of Saudi Arabia, 2013. J Family Med Prim Care. 2015;4(3):342.

7. Kasule OHK. Outstanding ethico-legal-fiqhi issues. J Taibah Univ Med Sci. 2012;7(1):5-12.

8. Aspriello SD, Ferrante L, Rubini C, Piemontese M. Comparative study of DFDBA in combination with enamel matrix derivative versus DFDBA alone for treatment of periodontal intrabony defects at 12 months post-surgery. Clin Oral Investig. 2011;15(2):225-232.

9. Yilmaz S, Cakar G, Yildirim B, Sculean A. Healing of two and three wall intrabony periodontal defects following treatment with an enamel matrix derivative combined with autogenous bone. J Clin Periodontol. 2010;37(6):544-550.

10. Güngörmüş Z, Güngörmüş $M$. Effect of religious belief on selecting of graft materials used in oral and maxillofacial surgery. J Oral Maxillofacial Surg. 2017;75(11):2347-2353.

11. Wang W, Yeung KWK. Bone grafts and biomaterials substitutes for bone defect repair: a review. Bioact Mater. 2017;2(4):224-247.

12. Alghamdi AS, Shibly O, Ciancio SG. Osseous grafting part II: xenografts and alloplasts for periodontal regeneration - a literature review. J Int Acad Periodontol. 2010;12(2):39-44.
13. Rathva VJ. Enamel matrix protein derivatives: role in periodontal regeneration. Clin Cosmet Investig Dent. 2011;3:79-92.

14. The noble Quran. 5:3, 6:145.

15. Ali R. Impossibility in Islamic Jurisprudence (Fiqh). 2013. Available from: https://www.iasj.net/iasj?func=fulltext\&aId=74548. Accessed January 1, 2018.

16. Agrama HA. Ethics, tradition, authority: toward an anthropology of the fatwa. Am Ethnologist. 2010;37(1):2-18.

17. Boynton PM, Greenhalgh T, Selecting GT. Selecting, designing, and developing your questionnaire. BMJ. 2004;328(7451):1312-1315.

18. Al-Johany S, Al Zoman HA, Al Juhaini M, Al Refeai M. Dental patients' awareness and knowledge in using dental implants as an option in replacing missing teeth: a survey in Riyadh, Saudi Arabia. Saudi Dent J. 2010;22(4):183-188.

19. Eriksson A, Burcharth J, Rosenberg J. Animal derived products may conflict with religious patients' beliefs. BMC Med Ethics. 2013; 14(1):48.

20. Mccarthy CR. Ethical aspects of animal to human xenografts. ILAR J. 1995;37(1):3-9.

21. Fernández RF, Bucchi C, Navarro P, Beltrán V, Borie E. Bone grafts utilized in dentistry: an analysis of patients' preferences. BMC Med Ethics. 2015;16(1):71.

22. Güngörmüş Z, Güngörmüş M. Effect of religious belief on selecting of graft materials used in oral and maxillofacial surgery. J Oral Maxillofac Surg. 2017;75(11):2347-2353.

23. Darwish S. The management of the Muslim dental patient. Br Dent J. 2005;199(8):503-504.

24. Halligan P. Caring for patients of Islamic denomination: critical care nurses' experiences in Saudi Arabia. J Clin Nurs. 2006;15(12):1565-1573.
Patient Preference and Adherence

\section{Publish your work in this journal}

Patient Preference and Adherence is an international, peer-reviewed, open access journal that focuses on the growing importance of patient preference and adherence throughout the therapeutic continuum. Patient satisfaction, acceptability, quality of life, compliance, persistence and their role in developing new therapeutic modalities and compounds to optimize

\section{Dovepress}

clinical outcomes for existing disease states are major areas of interest for the journal. This journal has been accepted for indexing on PubMed Central. The manuscript management system is completely online and includes a very quick and fair peer-review system, which is all easy to use. Visit http://www. dovepress.com/testimonials.php to read real quotes from published authors. 